\title{
Detecting Cosmetic Debt Management Using Benford's Law
}

Dominique Geyer, Audencia Nantes School of Management, France Christoph Drechsler, University College of Dublin, Ireland

\begin{abstract}
Benford's law states that the frequency of first significant digit in certain samples decreases as those digits increase. This law is used in accounting to find rounding behavior. Several studies provided evidence that firms may round up earnings when they are just below reference points denoted by $\mathrm{Nx}_{10} \mathrm{k}^{k}$. Most studies are focused on earnings variables. Few studies are focused on other accounting variables like sales for example (Jordan \& Alii, 2009; Geyer, 2012). No previous study examines accounting variable from balance sheet (excepted earnings of course). The aim of this short paper is to investigate rounding behavior of long term debt. Using a sample of US public companies, we observe that US firms round down the total long term debt considering two cognitive points: $N \times 10^{k}$ and $(2 \times N+1) \times 5 \times 10^{j}(N$ is an integer between 1 to $9 ; k$ is an integer from 1 and $j$ is an integer from 0). In other words, US public firms exercise Cosmetic Debt Management.
\end{abstract}

Keywords: Cosmetic Debt Management; Benford's Law; Rounding Behavior

\section{INTRODUCTION}

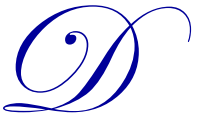

igital analysis is an audit technique that is applied to data sets to detect data anomalies. This technique uses Benford's law which gives the expected patterns of the digits in tabulated data. In the accounting literature, digital analysis reveals rounding behavior by comparing the expected frequencies of Benford's law and the actual frequencies of the reported accounting data. For example, a public firm has a positive earnings of $\$ 3,990,000$. The managers of the firm are motivated to round up earnings to $\$ 4,000,000$ because the stakeholders would perceive reported earnings of $\$ 4,000,000$ as being significantly better than reported earnings of $\$ 3,990,000$. Consider a sample of positive earnings from a population of public companies. If many managers have the same rounding up behavior, digital analysis will show more zeros and fewer nines as the second digit of positive earnings than could be expected under randomness. Kinnunen and Koskela (2003) described such practice as Cosmetic Earnings Management. Most prior studies in the accounting literature consider earnings or sales to study rounding behavior. No previous study examines rounding behavior from a debt item.

The purpose of this paper is to search inconsistencies in the patterns of the total long term debt (hereafter TLTD) numbers for a sample of U.S. public companies. In other words, we are searching for rounding behavior.

The results indicate that U.S. firms round down the total long term debt in 2010 and 2011. Unlike previous studies, we find two cognitive points: $\mathrm{Nx} 10^{\mathrm{k}}$ and $(2 \times \mathrm{N}+1) \times 5 \times 10^{\mathrm{j}}(\mathrm{N}$ is an integer between 1 to 9 ; $\mathrm{k}$ is an integer from 1 and $\mathrm{j}$ is an integer from 0 ). These results are not due to chance because we do not observe this rounding down behavior for the control variable total assets.

The remainder of the paper is organized as follows. In Section 2, we present Benford's law which is useful to detect unusual patterns in data. A brief overview of the previous literature on the phenomenon of rounding behavior of accounting data is presented in Section 3. The methodology and the sample selection procedures are discussed in Section 4. In Section 5, we present this study's empirical results. Conclusions and limitations of the study are exposed in Section 6. 


\section{BENFORD'S LAW AND DIGITAL ANALYSIS}

In this short paper, we submit the TLTD data from a sample of US public companies to digital analysis. In order to test the hypothesis of rounding behavior of this data, we need to compare the expected frequencies of the digits of TLTD with the actual frequencies. However, the true distribution of the digits absent of managerial manipulation of reported TLTD is not publicly observable. So we need a theoretical distribution for the comparison. Benford's law provides such a theoretical distribution. If asked to give the probability of getting a TLTD number with a first significant digit of 1 from a sample of US public companies' TLTD, most would incorrectly say 1/9 (the probability is $1 / 9$ because the first significant digit is between 1 to 9; 0 cannot be the first digit). This answer assumes that the first significant digits of TLTD numbers are equally likely. But it isn't the case. Benford (1938) observed that in many data sets the leading significant digit is not uniformly distributed among the digits (from 1 to 9) as one might expect; rather the lower digits appear much more frequently than the higher ones.

He proposes the following equation to calculate the probability that a number has a certain first digit a (for example, the three numbers 12,158 , and 1,899 have the same first digit 1):

Equation 1: $\quad \mathrm{P}($ first digit $=\mathrm{a})=\log _{10}\left(1+\mathrm{a}^{-1}\right)$ with a is an integer between 1 to 9 .

Hence, the probability of getting a number with 1 as first digit is:

$\mathrm{P}($ first digit $=1)=\log _{10}\left(1+1^{-1}\right)=0.30103$

The previous equation is extended to the general law given by:

Equation 2: $\quad P\left(D_{1} \ldots D_{k}=d_{1} \ldots d_{k}\right)=\log _{10}\left(1+\left(d_{1} \ldots d_{k}\right)^{-1}\right)$

For example, the probability of getting a number with the first two digits of 23 is:

$\mathrm{P}\left(\mathrm{D}_{1} \mathrm{D}_{2}=23\right)=\log _{10}\left(1+(23)^{-1}\right)=0.01848$

To determine the probability to have 1 as second digit, Equation 2 gives:

$\mathrm{P}\left(\mathrm{D}_{1} \mathrm{D}_{2}=11\right)+\mathrm{P}\left(\mathrm{D}_{1} \mathrm{D}_{2}=21\right)+\mathrm{P}\left(\mathrm{D}_{1} \mathrm{D}_{2}=31\right)+\mathrm{P}\left(\mathrm{D}_{1} \mathrm{D}_{2}=41\right)+\mathrm{P}\left(\mathrm{D}_{1} \mathrm{D}_{2}=51\right)+\mathrm{P}\left(\mathrm{D}_{1} \mathrm{D}_{2}=61\right)+\mathrm{P}\left(\mathrm{D}_{1} \mathrm{D}_{2}=71\right)+$ $P\left(D_{1} D_{2}=81\right)+P\left(D_{1} D_{2}=91\right)=0.11389$

Table 1 exhibits the frequencies for the first and the second digit in a data set which obeys Benford's law.

Table 1: Benford's Law: Expected Digital Frequencies

\begin{tabular}{|l|c|c|}
\cline { 2 - 3 } \multicolumn{1}{c|}{} & \multicolumn{2}{c|}{ Position in Number } \\
\hline 0 & 1st & 2nd \\
\hline 1 & & 11.968 \\
\hline 2 & 30.103 & 11.389 \\
\hline 3 & 17.609 & 10.882 \\
\hline 4 & 12.494 & 10.433 \\
\hline 5 & 9.691 & 10.031 \\
\hline 6 & 7.918 & 9.668 \\
\hline 7 & 6.695 & 9.337 \\
\hline 8 & 5.799 & 9.035 \\
\hline 9 & 5.115 & 8.757 \\
\hline
\end{tabular}

The range between the first digit 1 and the first digit 9 is large because it represents $25.5 \%(30.103 \%$ $4.576 \%)$. But for the second digit, the range decreases to $3.5 \%(11.968 \%-8.5 \%)$. Moreover, from the fifth digit, the frequencies are 10 percent for the ten digits. 
Table 2 shows an example of an accounting variable - total assets - which follows Benford's law. The sample concerns the total assets numbers of US Public Firms in 2010 and 2011. In 2010 and 2011, the frequencies of the ten second digits are not significantly different from their expectation 19 times out of 20 . We find only in 2010 more eights as second digits than could be expected under randomness $(\mathrm{p}$-value $=0.038)$. But this excess alone doesn't constitute a rounding behavior because there are not more zeros as second digits than could be expected under randomness. As can be seen from Table 2, the observed frequencies of the first digits of Total Assets are very close to Benford's theoretical frequencies. The Chi-square test isn't significant at 10 percent level in 2010 and 2011.

Table 2: Frequency of First Digits for Total Assets

\begin{tabular}{|c|c|c|c|c|c|c|c|}
\hline Digit & $\begin{array}{r}\text { No. } \\
\text { occurs }\end{array}$ & $\begin{array}{l}\text { aes digit } \\
\text { st position }\end{array}$ & $\begin{array}{c}\text { Observed frequency } \\
(\%)\end{array}$ & $\begin{array}{c}\text { Expected } \\
\text { Frequency }(\%) \\
\end{array}$ & $Z$ value & $P$ value & \\
\hline \multirow{2}{*}{1} & 2010 & 1,462 & 29.685 & \multirow{2}{*}{30.103} & -0.639 & 0.523 & \\
\hline & 2011 & 1,210 & 29.936 & & -0.232 & 0.817 & \\
\hline \multirow{2}{*}{2} & 2010 & 909 & 18.457 & \multirow{2}{*}{17.609} & 1.562 & 0.118 & \\
\hline & 2011 & 693 & 17.145 & & -0.774 & 0.439 & \\
\hline \multirow{2}{*}{3} & 2010 & 634 & 12.873 & \multirow{2}{*}{12.494} & 0.805 & 0.421 & \\
\hline & 2011 & 519 & 12.840 & & 0.666 & 0.506 & \\
\hline \multirow{2}{*}{4} & 2010 & 481 & 9.766 & \multirow{2}{*}{9.691} & 0.179 & 0.858 & \\
\hline & 2011 & 424 & 10.490 & & 1.717 & 0.086 & \\
\hline \multirow{2}{*}{5} & 2010 & 376 & 7.635 & \multirow{2}{*}{7.918} & -0.737 & 0.461 & \\
\hline & 2011 & 297 & 7.348 & & -1.342 & 0.179 & \\
\hline \multirow{2}{*}{6} & 2010 & 298 & 6.051 & \multirow{2}{*}{6.695} & -1.809 & 0.071 & \\
\hline & 2011 & 283 & 7.001 & & 0.780 & 0.436 & \\
\hline \multirow{2}{*}{7} & 2010 & 275 & 5.584 & \multirow{2}{*}{5.799} & -0.646 & 0.518 & \\
\hline & 2011 & 217 & 5.369 & & -1.171 & 0.242 & \\
\hline \multirow{2}{*}{8} & 2010 & 284 & 5.766 & \multirow{2}{*}{5.115} & 2.075 & 0.038 & \\
\hline & 2011 & 217 & 5.369 & & 0.732 & 0.464 & \\
\hline \multirow{2}{*}{9} & 2010 & 206 & 4.183 & \multirow{2}{*}{4.576} & -1.321 & 0.187 & \\
\hline & 2011 & 182 & 4.503 & & -0.223 & 0.823 & \\
\hline \multirow{2}{*}{ Total } & 2010 & 4,925 & Chi-square & 12.589 & Degrees of freedom 8 & P-value & 0.127 \\
\hline & 2011 & 4,042 & Chi-square & 7.654 & Degrees of freedom 8 & P-value & 0.468 \\
\hline
\end{tabular}

Of course all data sets do not conform to Benford's Law. Durtschi et al. (2004) distinguish several cases in accounting and auditing when Benford Analysis is not likely useful:

- $\quad$ Data set is comprised of assigned numbers (examples: check numbers, invoice numbers, zip codes)

- Numbers that are influenced by human thought (examples: prices set at psychological thresholds, ATM withdrawals)

- $\quad$ Accounts with a large number of firm-specific numbers (example: an account specifically set up to record \$ 100 refunds)

- $\quad$ Accounts with a built in minimum or maximum (example: set of assets that must meet a threshold to be recorded)

\section{LITERATURE REVIEW}

To detect rounding behavior or fraud in accounting data, once compared the digit distribution of the data set with the theoretical distribution of Benford's law. If the accounting data set isn't conformed to Benford's law, there is some level of suspicion. In the literature review, we consider only rounding behavior of accounting data extracted from the financial statements. However, Benford's law is used to analyze other kind of data: Tax returns on the U.S. Internal Revenue Service Individual Tax Model Files (Nigrini, 1996), scientific data (Diekman, 2007), survey data (Judge \& Schechter, 2009), etc.

Carlslaw (1988) is the first who detects rounding behavior in accounting. He finds a higher than expected frequency of zero and a lower expected frequency of nine as the second digit in reported earnings in a sample of 
New Zealand firms. The aim of this round up behavior is to achieve a key cognitive reference points of Nx10 $0^{\mathrm{k}}$. For example, earnings of $\$ 799,000$ may be perceived by investors to be much lower than $\$ 800,000$. So managers have incentives to report rounded earnings to change the behavior of investors. Thomas (1989) finds similar patterns in reported earnings for US firms. He extends his analysis at the per share level and noted that multiples of 5 cents and 10 cents are considerably more often observed than other numbers.

After this two pioneering studies, several papers examine rounding behavior of other accounting data or other countries (see Table 3).

Table 3: Literature on Benford's Law in Accounting Data

\begin{tabular}{|l|c|c|c|}
\hline \multicolumn{1}{|c|}{ Author(s) } & Year & Accounting Variable & Region \\
\hline Carlslaw & 1988 & Net income and ordinary income (second digit) & New Zealand \\
\hline Thomas & 1989 & Earnings and losses, quarterly earnings, earnings per share (second digit) & USA \\
\hline Niskanen and Keloharju & 2000 & Earnings (second digit) & Finland \\
\hline Van Caneghem & 2002 & Pre-tax income (second digit) & UK \\
\hline Van Caneghem & 2004 & Pre-tax income (second digit) & UK \\
\hline Kinnunen and Koskela & 2003 & Net income and net losses (second digit) & USA \\
\hline Das and Zhang & 2003 & Earnings per share (second digit) & Japan \\
\hline Skousen and al. & 2004 & Earnings (first, second, third and fourth digit) & USA \\
\hline Johnson & 2009 & Net income and earnings per share (first digit) & USA \\
\hline Jordan, Clark and Hames & 2009 & Sales Revenue (second digit) & USA \\
\hline Jordan and Clark & 2011 & Positive income (second digit) & USA \\
\hline Geyer & 2012 & Sales (second digit) & USA \\
\hline Hsien Hsieh and Lin & 2013 & Quartely earnings (second digit) & \\
\hline
\end{tabular}

Table 3 shows that previous studies concerns always earnings or sales. At the present time, to the best of our knowledge no previous study examine debt data from balance sheet to find rounding behavior. Stolowy and Breton (2003) elaborate a general framework for classifying accounts manipulations. Their framework is based on the desire to influence the market participants' perception of the risk associated to the firm. The risk is materialized through the earnings per share and the debt/equity ratio. Regarding the first ratio, earnings has been extensively examined in digital analysis. Most empirical studies focus on earnings variables. Only the studies by Jordan, Clark, and Hames (2009) and Geyer (2012) analyze another item: sales. Regarding the second ratio, debt was not submitted yet to digital analysis. The aim of this paper is to search rounding behavior in the total long term debt numbers in a sample of US public firms.

\section{METHODOLOGY}

Table 3 shows that prior empirical studies have used a number of different earnings variables such as ordinary income or earnings before extraordinary items and discontinued operations (Carlslaw, 1988; Thomas, 1989), pre-tax income (Van Caneghem, 2002), net income (Carlslaw, 1988; Niskanen \& Keloharju, 2000; Kinnunen \& Koskela, 2003), earnings per share (Thomas, 1989; Das \& Zahang, 2003), etc. In other words, there is no unanimity in the choice of the earnings level for digital analysis.

Concerning the debt, we have no previous study so the study is explanatory. Because of the difficulties in determining the most plausible target of Cosmetic Debt Management, we consider TLTD as a first choice. We use total assets as a control variable. There is no reason that management would round the total assets numbers to achieve cognitive reference points. For earnings variables, prior studies find upward rounding. Of course for TLTD, we expect a downward rounding behavior.

To notice a rounding behavior, we are searching one or more cognitive points. In other words, there will be an abnormally higher than expected occurrence of one (or more) digits in the second position of TLTD numbers. Of course this phenomenon isn't observed for the control variable total assets.

To test whether the deviation of observed frequency for any digit from its expected frequency is statistically significant, we use the standard normal z-statistic. To test the statistical significance of the whole distribution of observed first or second digits against its expectation under randomness, we use the Chi-square test. 
Data used in this study were obtained from the Standard \& Poor's Research Insight database. The empirical analysis includes annual net incomes of both active and inactive firms listed on New York Stock Exchange (NYSE), American Stock Exchange (AMEX), and National Association of Securities Dealers Automated Quotations (NASDAQ) for 2010 and 2011. It is useful to have two samples to note if a significant excess or lack of a second digit is present in the two samples. Otherwise it is maybe a statistical aberration which is often present in one sample and missing in the other one.

\section{EMPIRICAL RESULTS}

Table 4 details the frequencies of second digits of the control variable total assets in 2010 and 2011 of our sample of US public companies (it is the same sample as for the data reported in Table 2). As in Table 2, the Chisquare test accepts the hypothesis that all digits are distributed according to the theoretical distribution of Benford's law at the 5\% level of significance in 2010 and 2011. The z-statistics indicate that only one of the second digits in 2011 is significant at the 0.05 level, and none in 2010. But once cannot consider this to be a rounding behavior because we do not observe significantly more zeros as second digits than what could be expected by mere chance according to Benford's law. This finding is consistent with the prior studies of Jordan, Clarke, and Hames (2009) and Geyer (2012), who choose the same control variable. The two studies did not find rounding behavior in the total assets data set.

Table 5 examines the frequencies of second digits of TLTD in 2010 and 2011. The results are very different in comparison with the control variable. The Chi-square test is significant at 1 percent level ( $\mathrm{p}$-value $=0.000$ for the two years). For the second digit position of TLTD and using a 0.05 alpha level, the study reveals that the observed frequency of every digit, zero through nine, differs by a statistically significant amount from its expected frequency six times out of twenty (only one time out of twenty for the control variable) for the two years. There are two important phenomena:

- $\quad$ Table 5 shows that there are systematically more zeros and fives in the second place of TLTD numbers. The proportion of zeros (fives), expected to be 11.97 (9.67) percent of the sample, is actually higher by 1.86 (1.17) percent of the sample in 2010 and 1.61 (1.64) percent of the sample in 2011. These large deviations are statistically significant at the one percent level.

- $\quad$ For the other cases, Table 5 reveals a statistically significant (i.e., at the 5 percent level of significance) lower than expected incidence of sevens (in 2011) and eights (in 2010) as second digit for our two samples.

How can we interpret these observations? There are two types of rounding behavior: upward or downward. Empirical studies of Table 3 consider only upward behavior. This behavior can be more or less aggressive. Thus several studies note more than expected zeros and less than expected nines as second digit of earnings numbers: it is the less aggressive rounding behavior. For example, an earnings of 99.9 millions of dollars is rounded to 100 millions of dollars. However the results of Niskanen and Keloharju (2000) in their examination of cosmetic earnings management among Finnish firms show that Finnish companies do not limit their rounding of the second earnings digit merely from nines to zeros. The authors found that the observed frequencies of sixes and sevens as second digit are significantly smaller than their expected frequencies. In other words, the upwards rounding behavior is more aggressive. Jordan, Clark, and Hames (2009) found similar results for a sample of U.S. public companies: the same type of aggressive manipulative behavior appears to be occurring with respect to reported sales revenue. The study demonstrates that firms report zeros in the second sales digit far more often than expected and report sevens in the second sales position much less often than expected (the differences between the actual and expected proportions were significant at the 0.10 level).

Table 5 shows that there are two cognitive reference points (more than expected zeros and fives as second digit): $\mathrm{Nx} 10^{\mathrm{k}}$ et $(2 \times \mathrm{N}+1) \times 5 \times 10^{\mathrm{j}}(\mathrm{N}$ is an integer between 1 to $9 ; \mathrm{k}$ is an integer from 1 and $\mathrm{j}$ is an integer from 0 ). A rounding behavior compatible with the findings of Table 5 is rounding down behavior taking the two reference points into account. Other studies must confirm this finding. But this kind of Cosmetic Debt Management reinforces the results of Table 5: an important excess of fives and zeros as second digit are significant at 1 percent level in 2010 and 2011. For the eight other digits $(1,2,3,4,6,7,8$, and 9), the actual frequencies are smaller than their expected frequencies 15 times out of 16 in the two samples (only two lacks of second digit are significant at 5 percent level). 
Table 4: Frequency of Second Digits for Total Assets

\begin{tabular}{|c|c|c|c|c|c|c|c|}
\hline Digit & $\begin{array}{r}\text { No. of } \\
\text { i }\end{array}$ & $\begin{array}{l}\text { ligit occurs } \\
\text { sition }\end{array}$ & $\begin{array}{c}\text { Observed frequency } \\
(\%)\end{array}$ & $\begin{array}{c}\text { Expected } \\
\text { Frequency }(\%) \\
\end{array}$ & $Z$ value & $P$ value & \\
\hline \multirow{2}{*}{0} & 2010 & 589 & 11.589 & \multirow{2}{*}{11.968} & -0.019 & 0.985 & \\
\hline & 2011 & 482 & 11.925 & & -0.085 & 0.933 & \\
\hline \multirow{2}{*}{1} & 2010 & 545 & 11.066 & \multirow{2}{*}{11.389} & -0.714 & 0.476 & \\
\hline & 2011 & 469 & 11.603 & & 0.429 & 0.668 & \\
\hline \multirow{2}{*}{2} & 2010 & 526 & 10.680 & \multirow{2}{*}{10.882} & -0.455 & 0.649 & \\
\hline & 2011 & 442 & 10.935 & & 0.109 & 0.914 & \\
\hline \multirow{2}{*}{3} & 2010 & 504 & 10.234 & \multirow{2}{*}{10.433} & -0.458 & 0.647 & \\
\hline & 2011 & 398 & 9.847 & & -1.220 & 0.223 & \\
\hline \multirow{2}{*}{4} & 2010 & 506 & 10.274 & \multirow{2}{*}{10.031} & 0.568 & 0.570 & \\
\hline & 2011 & 404 & 9.995 & & -0.076 & 0.939 & \\
\hline \multirow{2}{*}{5} & 2010 & 473 & 9.604 & \multirow{2}{*}{9.668} & -0.152 & 0.879 & \\
\hline & 2011 & 402 & 9.946 & & 0.597 & 0.550 & \\
\hline \multirow{2}{*}{6} & 2010 & 451 & 9.157 & \multirow{2}{*}{9.337} & -0.433 & 0.665 & \\
\hline & 2011 & 403 & 9.970 & & 1.384 & 0.166 & \\
\hline \multirow{2}{*}{7} & 2010 & 479 & 9.726 & \multirow{2}{*}{9.035} & 1.691 & 0.091 & \\
\hline & 2011 & 382 & 9.451 & & 0.922 & 0.357 & \\
\hline \multirow{2}{*}{8} & 2010 & 439 & 8.914 & \multirow{2}{*}{8.757} & 0.389 & 0.697 & \\
\hline & 2011 & 307 & 7.595 & & -2.613 & 0.009 & \\
\hline \multirow{2}{*}{9} & 2010 & 413 & 8.386 & \multirow{2}{*}{8.500} & -0.287 & 0.774 & \\
\hline & 2011 & 353 & 8.733 & & 0.532 & 0.595 & \\
\hline \multirow{2}{*}{ Total } & 2010 & 4,925 & Chi-square & 4.120 & Degrees of freedom 9 & P-value & 0.903 \\
\hline & 2011 & 4,042 & Chi-square & 10.837 & Degrees of freedom 9 & P-value & 0.287 \\
\hline
\end{tabular}

Table 5: Frequency of Second Digits for Total Long Term Debt

\begin{tabular}{|c|c|c|c|c|c|c|c|}
\hline Digit & \multicolumn{2}{|c|}{$\begin{array}{l}\text { No. of times digit occurs } \\
\text { in } 2^{\text {nd }} \text { position }\end{array}$} & $\begin{array}{c}\text { Observed Frequency } \\
(\%)\end{array}$ & $\begin{array}{c}\text { Expected } \\
\text { Frequency }(\%)\end{array}$ & $Z$ value & $P$ value & \\
\hline \multirow{2}{*}{0} & 2010 & 681 & 13.827 & \multirow{2}{*}{11.968} & 4.020 & 0.000 & \\
\hline & 2011 & 549 & 13.582 & & 3.162 & 0.002 & \\
\hline \multirow{2}{*}{1} & 2010 & 518 & 10.518 & \multirow{2}{*}{11.389} & -1.925 & 0.054 & \\
\hline & 2011 & 450 & 11.133 & & -0.512 & 0.609 & \\
\hline \multirow{2}{*}{2} & 2010 & 544 & 11.046 & \multirow{2}{*}{10.882} & 0.369 & 0.712 & \\
\hline & 2011 & 449 & 11.108 & & 0.462 & 0.644 & \\
\hline \multirow{2}{*}{3} & 2010 & 495 & 10.051 & \multirow{2}{*}{10.433} & -0.878 & 0.380 & \\
\hline & 2011 & 415 & 10.267 & & -0.345 & 0.730 & \\
\hline \multirow{2}{*}{4} & 2010 & 459 & 9.320 & \multirow{2}{*}{10.031} & -1.661 & 0.097 & \\
\hline & 2011 & 377 & 9.327 & & -1.490 & 0.136 & \\
\hline \multirow{2}{*}{5} & 2010 & 534 & 10.843 & \multirow{2}{*}{9.668} & 2.789 & 0.005 & \\
\hline & 2011 & 457 & 11.306 & & 3.525 & 0.000 & \\
\hline \multirow{2}{*}{6} & 2010 & 435 & 8.832 & \multirow{2}{*}{9.337} & -1.217 & 0.224 & \\
\hline & 2011 & 354 & 8.758 & & -1.265 & 0.206 & \\
\hline \multirow{2}{*}{7} & 2010 & 439 & 8.914 & \multirow{2}{*}{9.035} & -0.297 & 0.767 & \\
\hline & 2011 & 318 & 7.867 & & -2.590 & 0.010 & \\
\hline \multirow{2}{*}{8} & 2010 & 392 & 7.959 & \multirow{2}{*}{8.757} & -1.980 & 0.048 & \\
\hline & 2011 & 333 & 8.238 & & -1.166 & 0.243 & \\
\hline \multirow{2}{*}{9} & 2010 & 428 & 8.690 & \multirow{2}{*}{8.500} & 0.479 & 0.632 & \\
\hline & 2011 & 340 & 8.412 & & -0.201 & 0.840 & \\
\hline \multirow{2}{*}{ Total } & 2010 & 4,925 & Chi-square & 33.043 & Degrees of freedom 9 & P-value & 0.000 \\
\hline & 2011 & 4,042 & Chi-square & 31.377 & Degrees of freedom 9 & P-value & 0.000 \\
\hline
\end{tabular}

\section{CONCLUSION}

The objective of this paper was to examine the total long term debt from a digital analysis point of view. An abnormality in the distribution of total long term debt numbers appearing in financial statements of U.S. public firms has been demonstrated. In other words, the aggregate frequency distribution of the second digits of total long term debt does differ from that expected under Benford's law (the Chi-square test is significant at 1 percent level), 
thus providing evidence of some management of total long term debt taking place, within the assumed framework of analysis for this study. We also find a significant positive deviation for zeros and fives for the second digit of total long term debt in 2010 and 2011. This is consistent with the notion that firms do downward rounding to reach two key cognitive reference points of $\mathrm{Nx}^{1} 0^{\mathrm{k}}$ and $(2 \times \mathrm{N}+1) \times 5 \times 10^{\mathrm{j}}(\mathrm{N}$ is an integer between 1 to $9 ; \mathrm{k}$ is an integer from $1 ; \mathrm{j}$ is an integer from 0 ).

These unusual patterns are not observed for the control variable total assets in 2010 and 2011: more zeros and more fives than expected by chance alone are not observed in the second digits of total assets and the Chi-square test is not significant at the one percent level.

Our study is exploratory, and there are several limitations. First, in this study, we consider only TLTD. Future research should consider further elements of debt such as current debt for example. Second our study investigates US public companies only. Future research could test our results using other samples such as private companies or public companies from other countries.

\section{ACKNOWLEDGEMENTS}

We wish to thank participants of the 2014 Munich International Business \& Education Conference for helpful comments.

\section{AUTHOR INFORMATION}

Dr. Dominique Geyer is Associate Professor at Nantes Audencia School of Management (France). He holds a $\mathrm{Ph} . \mathrm{D}$. from the University of Lille (France). His primary teaching areas are financial accounting and management accounting information systems. He has published articles in numerous journals, including Revue Francaise de Gestion, Systeme d'Information et Management, European Management Journal, Journal of Computer Information Systems, Information and Management, Journal of Business Economics Research, and Journal of Applied Business Research. Audencia Nantes School of Management, 8 route de la Joneliere BP 31222, 44312 Nantes Cedex 3, France. E-mail: dgeyer@audencia.com (Corresponding author)

Dr. Christoph Drechsler joined the accounting faculty at UCD Business Schools after receiving a PhD in Management (Major: Managerial Accounting and Control) from Hautes Etudes Commerciales (HEC), Paris/France. A qualified bank business management assistant, he has credit analyst experience with private bank Trinkaus \& Burkhardt, Düsseldorf/Germany (now part of HSBC). Christoph has been serving as Academic Director of the Smurfit School's MSc in Strategic Management Accounting, and as UCD faculty representative in the CEMS network (environmental management). He has extensive managerial accounting teaching experience in the Smurfit School MBA programmes and in executive education courses. University College of Dublin, Quinn School of Business, Belfield, Dublin 4, Ireland. E-mail: christoph.drechsler@ucd.ie

\section{REFERENCES}

1. Benford, F. (1938). The law of anomalous numbers. Proceedings of American Philosophical Society, 78(4), 551-572.

2. Carlslaw, C. (1988). Anomalies in income numbers: Evidence of goal oriented behavior. The Accounting Review, 63(2), 321-327.

3. Diekman, A. (2007). Not the first digit! Using Benford's Law to detect fraudulent scientific data. Journal of Applied Statistics, 34(3), 321-329.

4. Durtschi, C., Hillison, W., \& C. Pacini. (2004). The effective use of Benford's Law in detecting fraud in accounting data. Journal of Forensic Accounting, 5, 17-33.

5. Das, S., \& Zhang H. (2003). Rounding-up in reported EPS, behavioural thresholds, and earnings management. Journal of Accounting and Economics, 35(1), 31-50.

6. Geyer, D. (2012). Digital analysis of sales and industry partition: An examination of U.S. public companies. The Journal of Applied Business Research, 28(2), 245-252. 
7. Hsien Hsieh, C., \& Lin, F. (2013). Applying digital analysis to detect fraud: An empirical analysis of US marine industry. Applied Economics, 45, 135-140.

8. Johnson, G. (2009). Using Benford's Law to determine if selected company characteristics are red flags for earnings management. Journal of Forensic Studies in Accounting and Business, 39-65.

9. Jordan, C. E., Clark, S. J., \& Hames, C. (2009). Manipulating sales revenue to achieve cognitive reference points: An examination of large U.S. public companies. The Journal of Applied Business Research, 25(2), 95-103.

10. Jordan, C. E., \& Clark, S. J. (2011). Detecting cosmetic earnings management using Benford's Law. The CPA Journal, 78(2), 32-37.

11. Judge, G., \& Schechter, L. (2009). Detecting problems in survey data using Benford's Law. Journal of Human Resources, 44(1), 1-24.

12. Kinnunen, J., \& Koskela, M. (2003). Who is miss world in cosmetic earnings management? A crossnational comparison of small upward rounding of net income numbers among eighteen countries. Journal of International Accounting Research, 2, 39-68.

13. Nigrini, M. J. (1996). A taxpayer compliance application of Benford's Law. Journal of the American Taxation Association, 18(1), 72-91.

14. Niskanen, J., \& Keloharju, M. (2000). Earnings cosmetics in a tax driven accounting environment: Evidence from Finnish public firms. European Accounting Review, 9(3), 443-452.

15. Thomas, J. K. (1989). Unusual patterns in reported earnings. The Accounting Review, 64(4), 773-787.

16. Skousen, J. C., Guan, L., \& Wetzel T. S. (2004). Anomalies and unusual patterns in reported earnings: Japanese managers round earnings. Journal of International Financial Management, 15(3), 212-234.

17. Van Caneghem, T. (2002). Earnings management induced by cognitive reference points. British Accounting Review, 34(2), 167-178.

18. Van Caneghem, T. (2004). The impact of audit quality on earnings rounding-up behaviour: Some UK evidence. European Accounting Review, 13(4), 771-786. 